\title{
Applied Mathematics in the Humanities: Review of Nonparametric Statistics for the Behavioral Sciences by Sidney Siegel and N. John Castellan, Jr. (2nd ed., 1988)
}

Paul H. Grawe

Winona State University and Institute for Travesty, Comedy, and Humor Studies, pgrawe@hbci.com

Follow this and additional works at: https://digitalcommons.usf.edu/numeracy

Part of the Arts and Humanities Commons, Physical Sciences and Mathematics Commons, and the Social and Behavioral Sciences Commons

\section{Recommended Citation}

Grawe, Paul H.. "Applied Mathematics in the Humanities: Review of Nonparametric Statistics for the Behavioral Sciences by Sidney Siegel and N. John Castellan, Jr. (2nd ed., 1988)." Numeracy 9, Iss. 1 (2016): Article 7. DOI: http://dx.doi.org/10.5038/1936-4660.9.1.7 


\title{
Applied Mathematics in the Humanities: Review of Nonparametric Statistics for the Behavioral Sciences by Sidney Siegel and N. John Castellan, Jr. (2nd ed., 1988)
}

\author{
Abstract \\ Sydney Siegel and N. John Castellan, Jr. Nonparametric Statistics for the Behavioral Sciences, Second \\ Edition (New York NY: McGraw Hill, 1988). 399 pp. ISBN: 9780070573574. \\ Almost 60 years ago, Sidney Siegel wrote a stellar book helping anyone in academe to use nonparametric \\ statistics, but ironically, 60 years after that achievement, American higher education confesses itself to be \\ in the worst Quantitative Teaching Crisis of all time. The key clue to solving that crisis may be in Siegel \\ and Castellan's title, Nonparametric Statistics for the Behavioral Sciences, which quietly and perhaps \\ unconsciously excludes the Humanities.
}

Yet it is in humanistic realities that students read, write, and think. This book review considers what could be done if the Humanities were made aware of the enormous power of nonparametric statistics for advancing both their disciplines and their students' ability to think quantitatively. A potentially revolutionary, humanistic, nonparametric finding is considered in detail along with a brief account of tens of humanistic discoveries deriving from Siegel and Castellan's impetus.

\section{Keywords}

statistics, nonparametric statistics, humanities, behavioral sciences, medieval studies, humor studies

\section{Creative Commons License}

\section{(c) (i) (8)}

This work is licensed under a Creative Commons Attribution-Noncommercial 4.0 License

\section{Cover Page Footnote}

Paul Grawe is widely published on empirical studies of humor and humor's relationship to comedy and claims long experience getting English majors interested in making empirical discoveries in the Humanities. He has been statewide Government Relations Co-chair for the faculties of the seven Minnesota state universities. 


\section{Introduction}

It was a strange thing to do, considerably more than "not quite the thing" for someone from English to do. Twenty five years ago, at a faculty-union dinner I sat down at a table of scientists.

Well yes, I had some cover for such bizarre behavior. For starters, I had an idea I wanted to check out for using commercial aircraft to fix the hole in the ozone layer. The ozone idea broke the ice pretty well, mainly with the scientists' uproarious laughter at my stupidity. For someone like me working in humor and comedy, this was a satisfactory opening gambit.

Since I was these scientists' representative in government relations at the statewide level, I wasn't terribly concerned with the loss of prestige. I could afford it, and I was trying to buy something pretty valuable, some greater knowledge of statistics to use in a classroom experiment I had recently devised. The follow-up question on statistics was at least as naïve as the question on ozone distribution. The answer to that question changed my life.

Instead of directly answering my question, Dr. Larry Reuter recommended Siegel and Castellan's Nonparametric Statistics for the Behavioral Sciences. Larry is a Princeton Ph.D. If he as a biologist could recommend this book, I decided I probably needed to accept his recommendation. It turned out to be an admirably concise volume, nowhere near the length of War and Peace, but I found that mathematics texts can out-price War and Peace any day. I admit to having been daunted by the price, but it was probably the best investment I ever made in academe.

So this is another strange thing to do, to write a review of a text that was over thirty years old when I first saw it in its second edition (Siegel's first edition was published in 1956). It is not nearly as strange as a tribute to a book that made such a difference for me. And it is even less strange as a testimonial clue to the solution of America’s Quantitative Literacy and Quantitative Reasoning crises. ${ }^{1}$

\section{The Situation 60 Years Ago}

Let's start with the situation 60 years ago. As Siegel's title in 1956 suggested, the behavioral sciences needed statistics in general and nonparametric statistics in particular. At that time, the best and the brightest social scientists were using statistics, and particularly nonparametric statistics, which often are greatly superior to parametric statistics both in theory and within the practical limits of

\footnotetext{
${ }^{1}$ Note from editor: Some readers may be aware of other books on nonparametric statistics. We know the author does not mean to imply that others won't prefer texts of more recent vintage. Simply put, we appreciate Humanities enthusiasts who savor a good text on the subject. - MC.
} 
working with human subjects. By 1988, Siegel allied himself with Castellan to present not just nonparametric statistics but also monumental discoveries in the behavioral sciences as exemplary of the nonparametric tests.

Notice, however, that the missionary efforts of Siegel and later Siegel and Castellan were constrained by their very title. Behavioral sciences, yes. Humanities, NO. The Humanities were the Great Unwashed (the GU). Unregenerate. Unredeemable. Siegel and Castellan never said a word of this. They didn't have to. No one would have to say it today.

\section{The Crisis Now}

Now 60 years later, no one in the Social Sciences needs to be told about nonparametric statistics. At the same time, the Quantitative Education Crisis has never been greater. ${ }^{2}$ And perhaps not coincidentally, even as post-2008 students look for useful (that is, paying-job preparation, relevant) majors, it may seem that the Humanities are on their way to the dustbin of history.

Well, it's been a long run for the Humanities_-2300 years if we arbitrarily start with Aristotle-so maybe it's time to strike the curtain. There is no doubt some small delight for scientists and social scientists in entertaining such ideas. But there is a profound catch to it. The catch takes a fairly extended proof, which also is a further clue for meeting the Quantitative Crisis.

One of my first great successes using Siegel and Castellan was to get a Bush grant for across-the-curriculum assessment of Winona State University's nurture of almost 300 critical-thinking variables (Grawe and Grawe 1995, 1996). The results were astounding as my co-researcher, sociologist Dr. Brian Aldrich, had already found in a prototype study.

What we found was that faculty from various departments all believe that we should be involved in teaching critical thinking. But faculty in various departments all emphasize quite distinct forms of thinking as what they appreciate as critical thinking.

The high-confidence, astounding result that Brian and I presented at the American Association of Higher Education, however, was that the forms of thinking that could be statistically shown to be nurtured at Winona State were the forms of critical thinking that the English Department valued (Aldrich and Grawe 1994).

Put another way, if education is not about specific facts but about the ability to read (including Quantitative Literacy), to write (including Quantitative Fluency,) and to think (including Quantitative Reasoning), then a major state

\footnotetext{
${ }^{2}$ As evidence, consider the number of publications, conferences, and even journals like Numeracy devoted to addressing the crisis.
} 
university with faculty trained here, there, and everywhere (and therefore likely to be quite typical of the entire profession) could be said to have nurtured, to have actively taught, what a central humanities discipline teaches. Do we have a Quantitative Crisis? Does that mean then that the Humanities are not teaching to meet the crisis and, thus, whole institutions are failing to teach to meet the crisis?

In many ways, this should not be a surprise. People, including student people, do not live in the Sciences or in the Behavioral Sciences. These are recent disciplines spun off by specialization. People live in their basic, characteristically dirty, often self-contradictory, indifferently honest humanity. They instinctively and-despite all academic attempts to the contrary-finally read, write, and think in their humanity. (They count, calculate, design, plan, build, evaluate, and prognosticate in numbers. In this sense, people including student people need, beyond the Humanities, to live in numbers and mathematics.)

So, here is finally the catch: if the Humanities are headed for the dustbin of history, something else will have to take their place as the nurturer of critical reading, writing, and thinking.

\section{Alternate Solutions}

With Siegel and Castellan's enormously talented contribution, it is impossible to say that the Behavioral Sciences are not up to speed. But that contribution to the Social Sciences notwithstanding, higher education in general is woefully failing to teach for a quantitative world.

Teaching to read, write, and think critically has typically been a Humanities specialty. If the Humanities are no longer available, then to replace them well, some professors in the Sciences or Behavioral Sciences must take years away from specialties they love and have chosen to pursue in order to prepare themselves to help students through the prosaic things that dominate life in every age. That's one possible solution.

An easier solution, using Siegel and Castellan, is to bring the Humanities a bit up to speed so that they can continue to teach to critically read, write, and think, but additionally teach to read, write, and think quantitatively.

The National Science Foundation in recent years has been giving grants to humanities faculty to do quantitative research. NSF's initiative recognizes the problem of getting the Humanities involved. But, the NSF approach too frequently assumes that the solution to academe's problem is that humanities professors need to find uses for ultra sound and green-light lasers in their disciplines.

The NSF approach, in short, often misses that the mission of the Humanities is not simply to become scientists. Scientists will be poorer for it if the Humanities forget that. And expensive equipment substituting for humanists 
advancing the Humanities will ultimately fail to win significant Humanities support.

What is needed instead, I have found over the last twenty five years, is not to use exotic scientific equipment but rather to take Siegel and Castellan seriously (and their book is a lot cheaper than the typical NSF grant) but also to take seriously the special-needs situation of the Humanities.

\section{Siegel, Castellan, and the Humanities: A Test Case}

So let's see what Siegel and Castellan can do for the Humanities that isn't as farfetched as ultra sound. Academe clearly needs to nurture quantitative reading, writing, and thinking leaning heavily on the Humanities in general-education settings. (Humanists typically are trained in deep specialties but disproportionately teach to students beyond their majors, i.e. in general-education settings.)

Assume a literature professor specializing in the Middle Ages and for years or even decades mulling things over. Our professor begins to suspect that there is some periodicity at work in medieval studies. Put mathematically, our humanist suspects something like a 100-year cycle in European medieval history.

Notice that however wacky and unscientific this may sound, our humanist is at least starting to think quantitatively. Our professor from the GU is not thinking scientifically because science demands replication, and our humanist has yet to figure out a way to replicate the Middle Ages in any experimental guise.

Now, what if a Siegel and Castellan came along and said, "No problem. Use the right nonparametric test with the right data, and we will refer you to our convenient table at the back of the book that will give you the probability that the null hypothesis can be discarded [humanistic translation: that you are onto something] to the fourth decimal place.”

Siegel and Castellan have essentially said just that.

They have written an immensely well-organized book, starting with a nononsense presentation of the assumptions underlying all nonparametric statistical tests. There turn out to be about six such assumptions, which is considerably less than the number for parametric statistics. And Siegel and Castellan explain everything so well that even a humanist can check her or his work against the nonparametric standards. From there, Siegel and Castellan start with the Binomial Test, essentially the test for deciding whether a coin toss that comes up 42 heads to 22 tails suggests that the coin cannot be trusted.

For the Binomial Test, and for every additional test, Siegel and Castellan show how to test (that is, how step-by-step to calculate) the statistical data for the likelihood that the apparent result of the data reflects a real difference. They, in 
fact, show how to calculate this probability both for small samples (typically less than 30) and for large samples.

Thus, the 42/22 result cited above can be calculated as a large sample, and a convenient appendix shows that such a discrepancy between heads and tails represents a real discrepancy (or bias) at a level of $98.24 \%$. The old saw is that 99\% is considered proved in the sciences and 95\% is considered proved for experiments using "dirty” human-reality data outside the sciences. So our coin not being a dirty human, we're a little short of proving the Case of the Biased Coin.

What is really wonderful, however, even more wonderful than the organized theory, even more wonderful than the example calculations for both small and large samples, is that Siegel and Castellan give real examples of how the test was actually used to make important discoveries in the Behavioral Sciences. And we can calculate along with them just how proved these discoveries were.

What is wonderful here is not the historical fact of behavioral-science discovery. It is instead the wonder of real-life examples of people using their heads, of inventing a test that can measure and can be used for statistical proof. And as every professor of rhetoric knows, invention is originally not a word from science but was 2000 years earlier the central concern of the Humanities and rhetoric.

In other words, Siegel and Castellan jump-start statistical imagination. And they don't have to go beyond the chapter on the Binomial Test to spark the thought necessary to solve the question of medieval 100-year cycles.

Have you figured out what data to test nonparametrically?

If you haven't, you are like just about everyone else. It is the invention, the design of a test that is the hard part. Siegel and Castellan incessantly teach this lesson by example. And then Siegel and Castellan make all the rest-the mathematical calculation-easy.

All fine, but now, really, this (the medieval stuff, that is) isn't fair, is it? The Middle Ages died a long time ago. We can't go back and gather data. Who cares anyway? This is pretty wacky stuff, and it won't earn kudos among humanities faculties even if there is an answer. So why not leave quantitative reasoning to the scientists and social scientists?

You get the drift.

This is the kind of thinking that has kept the Humanities out of Quantitative Reasoning since Aristotle and the Greek scientific attitude. It is often said that Greek science was never willing to get its hands dirty by actually experimenting. So Greek science went enormous distances in mathematics that was all heady stuff and went almost nowhere in medicine where people were dying and perhaps even went retrograde in chemistry, astronomy, and geology. And most of the time, the Greeks and later the Romans and even later the medieval Europeans put their time mainly into religion, philosophy, rhetoric and 
the other really important things. Finally came the Scientific Revolution that gave us all the necessary things like bi-focal glasses, radiation treatments, space travel, Teflon ${ }^{\circledR}$, smart phones, and atomic weaponry.

We could quarrel over all of this. And academics have quarreled over it for ages. We can't afford, however, to continue the quarrel because everyone knows that we live in a quantitative world and that we aren't adequately preparing our students to read, write, and think in that quantitative world.

So instead, let's offer the Humanities Siegel and Castellan's achievement: nonparametric statistics lucidly presented, carefully organized and justified, but most importantly exemplified as invention in the "dirty" world of human-subject inquiry.

Still stumped on nonparametric data for the 100-year cycle? Well, at least you know why you're not the only one.

But really, there is a readily available test, and having read Siegel and Castellan, one may have caught the imaginative flame necessary to burn through the Gordian knot instead of just cutting through it with an unproved assertion of a century cycle.

One of the great facts of the medieval world after 1000 A.D. was the founding of universities. And another great fact is that universities always remember when they were founded.

So let's get a list of all the European universities founded between 1000 and 1500. While we're at it, let's get a list of the founding of all the Oxbridge colleges - the Brits always have their own idiosyncratic approach.

And let's let our assumed GU professor sound almost scientific by proposing a(n) hypothesis: the founding dates of the European universities and British colleges will not be evenly distributed within centuries but will instead concentrate in some fraction of the years of the century. This consistent tendency will indicate a century cycle in action.

This is a pretty open-ended hypothesis, and I expect many scientists to jeer. But with the present state of quantitative work in the Humanities, this hypothesis is about the best our professor from the GU can do for now. When she or he has gotten her or his respective hands dirty in the data for quite a while, perhaps our professor will be able to make some much more precise hypothesis. For the present, however, a more precise hypothesis would be mountebank grandstanding and nothing more.

Now I have actually done this study (perhaps someone has even published on it), and I actually found that European-university and British-college founding dates are quite limited to a contiguous $2 / 3$ of the years of centuries. The first European university, Bologna, founded in 1088, at which I have had the privilege of presenting a paper on humor (Grawe 2002), is very near the center of that 
pattern. I mention presenting a paper because it shows how easy it is to get such data. I was not going to get out alive without knowing how old Bologna was.

But back to Siegel and Castellan. Long before the end of Chapter 4, I should know what to do with this university-and-college data. I should be able to say whether there is a $10 \%$ chance that I'm on to something about a century cycle, or a $75 \%$ chance, or a $90 \%$ chance, or a $97.52 \%$ chance.

Happily, Siegel and Castellan are not unduly fixated on the idea of proof = 95\% confidence. And neither should anyone in the humanities be. Say that when I run the Binomial Test, I get the estimated result that it is $89.37 \%$ probable. It seems fashionable these days to throw out such results as unproved. There is, after all, a $10.63 \%$ chance that I am wrong, that this is a false positive, which Siegel and Castellan with all statisticians explain in detail.

But if you are in the Humanities, you should know that you are worlds more quantitative to have a result that is $89 \%$-confident (likely to be substantiated 8 times out of 9) than to have just a strong hunch inside yourself. I'll take an $89 \%$ probability of a major medieval reality everyday over anybody's hunch.

We're back to the special-needs situation of the Humanities. Truth to tell, for many in the GU, even a claim of $85 \%$ confidence is so unimaginably high as to be vulgarly précieux. More special need.

Notice that I don't have to just take the $89 \%$ estimate. I hypothesized that there is a century cycle. Perhaps there are other data sets - the founding of monasteries, for example - that can mesh with my original data set.

But before seeking other data sets, maybe it is really a 98-year cycle or maybe a 102-year cycle. The same data that I've used to test my century hypothesis can be equally used for a test of the 98-year or the 102-year hypothesis.

And maybe one of those tests is provable at the 95\%-confidence level. Everyone seems to think subconsciously in century terms (another humanities special need: in considering human questions, people who have never systematically studied any of it still think they are authorities-which in a certain sense they are; authorities, however, do not always come to true conclusions). Maybe their universal assumption needs a little tweaking.

Since I've mentioned tweaking unabashedly, let me add that yes, I know that there are all sorts of mathematical arguments about "fishing trips" and "gaming" statistics. Siegel and Castellan give us all the ground rules we should need to enter such discussions.

But the fact for me in the Humanities is that in such an inquiry, I am in a dark room, looking to at least dimly distinguish furniture I might otherwise stumble over (again a special need of the Humanities). Everybody assumes centuries. As an honest GU investigator, I have a responsibility to check whether there is evidence that everyone's thinking could be improved. 
Anyway, I'd rather strike a controversial match than snuff an illuminating candle.

If it turns out that I have a provable 97-year cycle, the mathematical quibbles about how many tests I ran to establish that reality will be nothing compared to the humanistic debates over what if anything the result means about the Middle Ages or perhaps even about today if the cycle is still operative.

\section{What Siegel and Castellan Did at ITCHS}

Siegel and Castellan's greatest achievement is to present a jump start for invention. We have just considered how inventing the right test could potentially reorient medieval studies.

For us at the Institute of Travesty, Comedy, and Humor Studies (ITCHS), that jump-started invention worked from a deep conviction that we humanists were wrong to talk about humor. Humor is singular. At ITCHS, we were convinced that humor should be plural. Siegel and Castellan provided impetus for us to identify four types of humor and to run them against each other in nonparametric tests.

Since then, associates and I have made statistically proved, humanisticsbased discoveries about humor by the tens, maybe by the score using just a few of Siegel and Castellan's tests. My students in a general-elective Comedy and Humor course have collected data that would, if published, add significantly to these published findings. Almost all our discoveries could be proved using the Binomial Test, the Chi Square Test, or the Wilcoxon-Mann-Whitney Ranks Test (Humor Quotient Newsletter 1994-2011).

Ranks tests turn out to be fun, tremendous work without a computer assist, and robustly and powerfully useful tools in many human-subject test areas. Because ranks tests are more robust, it is possible that simply applying a Wilcoxon-Mann-Whitney Ranks Test produces an estimate closer to the magic 95\%-confidence level.

Siegel and Castellan arrange test discussions in order of design sophistication (the Wilcoxon Test is found only a third of the way through), and there are many tests in the later chapters that I cannot imagine using, much as I admire the robustness of their confidence estimates and the sophistication of their test designs.

Probably that shows a lack of creative, inventive imagination on my part. My hope is that, seeing what Behavioral Science has achieved through nonparametric statistics as presented in Siegel and Castellan and seeing what can be done in the Humanities with the simplest of nonparametric tests, humanists and their students will become much more inventive than I could have dreamed in areas of 
Quantitative Reasoning, Quantitative Literacy, and Quantitative Humanistic Discovery.

\section{Conclusion}

This paper is meant as a commendatory, testimonial review of a book now approaching its $60^{\text {th }}$ birthday, Siegel and Castellan's Nonparametric Statistics for the Behavioral Sciences. I can't think of a better testimonial than showing how Siegel and Castellan in their entire enterprise can free not just the Behavioral Sciences but also the Humanities to actually think that numbers matter, to use them to test important ideas, and to make discipline re-invigorating discoveries.

Returning to our hypothesized medieval specialist, if our medievalist can somehow be induced to think things through quantitatively this far, don't we have to think that in her or his general electives courses, she or he will be helping students much more to read, write, and think quantitatively?

I unequivocally recommend Nonparametric Statistics for the Behavioral Sciences for its conciseness, its organization, its lucidity, its thorough presentation of both theory and calculation to everyone in academe but particularly to humanists wanting to advance the Humanities and to everyone in the Humanities who wants students to think better in a quantitative world.

Most of all, I recommend Siegel and Castellan as a jump start for test invention.

\section{References}

Aldrich, B. and P. Grawe. 1994. Program-level assessment of composition-related critical thinking. Washington, D.C: American Association of Higher Education Conference on Assessment in Higher Education.

Grawe, P. 2002. The double humor structure and personality of Shakespeare's Tempest. Bertinoro, Italy: International Humor Conference of the International Society of Humor Studies.

Grawe, P. and R. Grawe. 1995. University-wide nurturance of critical-thinking skills: Assessment with personality-proclivity diagnosis. Boston, MA: Tenth American Association of Higher Education Conference on Assessment \& Quality.

- 1996. Truth in nurture: Assessing the institution's critical thinking commitment. Chicago, IL: 101st Annual Meeting of the North Central Association.

Humor Quotient Newsletter. 1994 - 2011. Winona, MN: Institute for Travesty, Comedy, and Humor Studies. http://www.itchs.org/HQN\%20contents.htm (accessed October 15, 2015).

Siegel, S. and N. J. Castellan, Jr. 1988. Nonparametric Statistics for the Behavior Sciences, second edition. New York, NY: McGraw-Hill. 